\title{
Numerical study on beam-column connection of cantilever precast concrete beam with asymmetric shape under static load
}

\author{
Hakas Prayuda ${ }^{1, *}$, Robbi'al Rollyas Syandy ${ }^{1}$, Bagus Soebandono ${ }^{1}$, Taufiq Ilham Maulana ${ }^{1}$, \\ and Martyana Dwi Cahyati ${ }^{1}$ \\ ${ }^{1}$ Department of Civil Engineering, Faculty of Engineering, Universitas Muhammadiyah Yogyakarta, \\ 55183 Lingkar Selatan Street Tamantirto Kasihan Bantul Yogyakarta, Indonesia
}

\begin{abstract}
Cantilever beams are generally used in all infrastructures, including precast concrete structures. In that type of structure, the asymmetric-section shape usage will be optimum and effective. However, in precast concrete structures, it might be susceptible especially in beamto-connection parts due to its strength. In this research, the damage mechanism of connections between cantilever beams and columns in precast concrete will be analyzed. The asymmetric shape will be applied in cantilever beams. Three samples were made with a length of $1500 \mathrm{~mm}$ equipped with six $10 \mathrm{~mm}$-diameter deformed rebar and stirrup with $6 \mathrm{~mm}$ diameter plain rebar. The results show that each of the three speciments has its own effectiveness based on stress, strain, displacement, load, and other related parameters.
\end{abstract}

\section{Introduction}

Beams are an important structural component, widely used for structural buildings, and usually used to support main loads on buildings and bridges [1]. Beams are intended to support majorly shear and flexural loads [2]. Beams can be made from various materials such as steel, concrete, wood, bamboo, or others. In buildings, there are several types of supports namely simple beams, continuous beams and cantilever beams. Cantilever beams are beams that are supported with fixed support on one side only, while the other side of the component is free supported. This type is very commonly used in the field, especially for outdoor purposes. This beam is very susceptible to high deflection in cases of overload [3]. Also, cantilever beams can be made with a precast system.

Studies on cantilever beams have been done before, for example regarding deflection and deformation [4-6], fracture and crack analysis [7-9], stress-strain relationship [10], and energy dissipation [11]. However, not all of these research results have been applied to the cantilevered structure with precast concrete. Precast is a concrete-making system popular in this century, and have often replaced conventional systems. Precast concrete is suitable for continuous work such as beam and column work. Additionally, the manufacture of concrete is done in factories, making this product more reliable in its quality and maintenance.

${ }^{*}$ Corresponding author: hakasprayuda@umy.ac.id 
In construction, a precast system consists of several parts arranged and connected to the whole structure, so that in this case there will be a weak point located at the connection among those precast components.

In this research, three specimens of cantilevered beam-based blocks of reinforced concrete of precast with three different shapes are discussed. It is hoped that from this research, the stress-strain relationship, P-delta relationship, stiffness, ductility, energy dissipation and the biggest point in receiving loads or damage, will be generated. Numerical methods were performed through the application of Abaqus CAE v6.13. Static load point is placed at the end of free-supported beam. This research is expected to increase the study of the connection system with various types of cantilever beams made of precast concrete.

\section{Samples and analysis method}

This study will analyze the performance of the precast cantilever beam connections. Three samples were numerically analyzed using Abaqus 6.13 software with data shown in Table 1. Each test object was converged first. The quality of concrete used $f^{\prime}{ }_{c}=28 \mathrm{MPa}$, and the Young's modulus of the reinforcing bar used is $200.000 \mathrm{MPa}$. From this numerical analysis an output of the P-delta relationship, stress-strain relationship and crack pattern that occurred, is generated.

Table 1. Detailed of sample variations used.

\begin{tabular}{|c|c|c|c|c|c|c|}
\hline \multirow[b]{2}{*}{ Samples } & \multicolumn{2}{|c|}{ Dimension (mm) } & \multirow{2}{*}{$\begin{array}{c}\text { Length } \\
(\mathrm{mm})\end{array}$} & \multirow{2}{*}{$\begin{array}{c}\text { Main } \\
\text { Reinforce }\end{array}$} & \multicolumn{2}{|c|}{ Shear Reinforce } \\
\hline & Fix point & $\begin{array}{l}\text { Free } \\
\text { Point }\end{array}$ & & & $\mathbf{M u}^{-}$ & $\mathbf{M u}^{+}$ \\
\hline BK-1 & $200 \times 175$ & $200 \times 175$ & 1500 & $6 \mathrm{D} 10$ & $\varnothing 6-80$ & $\varnothing 6-40$ \\
\hline BK-2 & $250 \times 175$ & $170 \times 170$ & 1500 & $6 \mathrm{D} 10$ & $\varnothing 6-80$ & $\varnothing 6-40$ \\
\hline BK-3 & $250 \times 175$ & $170 \times 170$ & 1500 & $6 \mathrm{D} 10$ & $\varnothing 6-80$ & $\varnothing 6-40$ \\
\hline
\end{tabular}

Details of the test samples in this research can be seen in Figure 1 to Figure 3. The given static point load is $30 \mathrm{kN}$ in the free-support. Sample 1 (BK-1) is a beam with a normal cross section where the fixed support and the free support have the same crosssectional dimension, while sample 2 (BK-2) and sample 3 (BK-3) are precast cantilever beams that are not symmetrical in their cross-sectional size. Its cross-section dimension at the fixed support is larger than the other. All test specimens use the same size and number of rebar, while the material properties of steel and concrete are not field-tested, all data is retrieved through prior research [12].
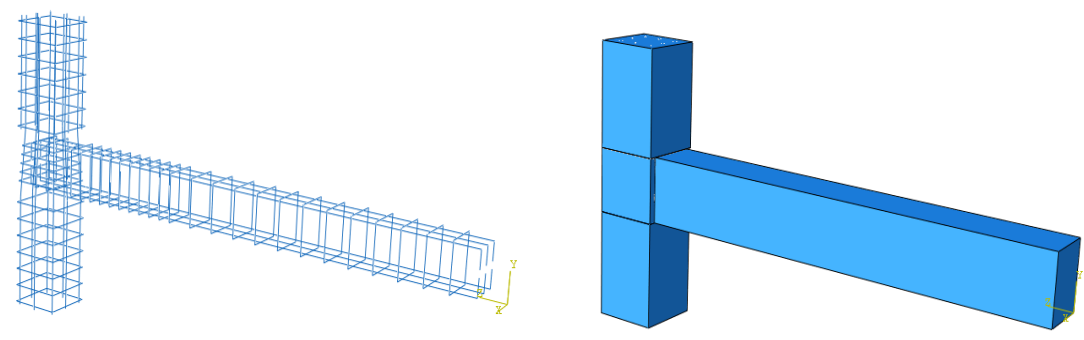

Fig. 1. Detail of Cantilever beam sample 1 (BK-1). 

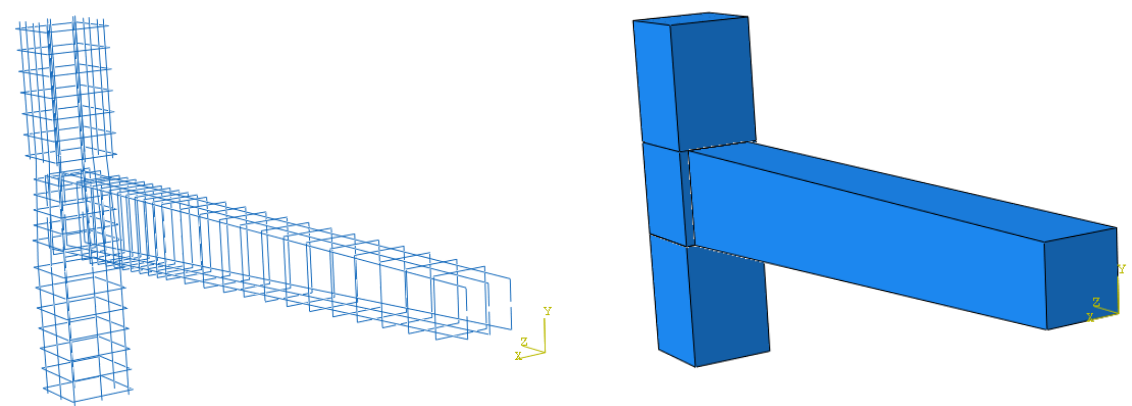

Fig. 2. Detail of Cantilever beam sample 2 (BK-2).
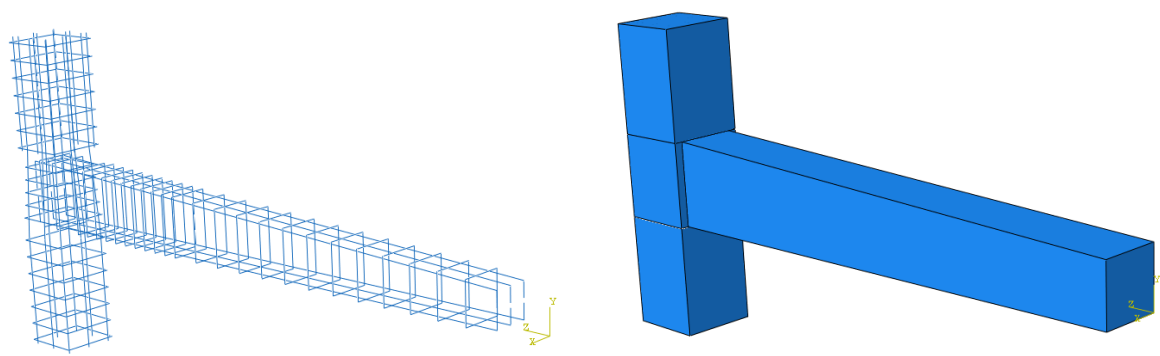

Fig. 3. Detail of Cantilever beam sample 2 (BK-2).

\section{Result and discussion}

\subsection{Convergence analysis}

Before further analysis is done, samples that have been created should be tested with a convergence test. This action aims to determine the exact number of mesh and reduce the error percentage. Figure 4 shows the relationship between number of mesh and the deflection that occurs; in this case, the mesh is stopped when the resulting deflection is constant or fixed. The three models have different amounts of mesh according to the condition of the specimen: for BK-1 the number of elements is 2746 , while for BK-2 it is 2790 and BK-3 it is 2846 . 


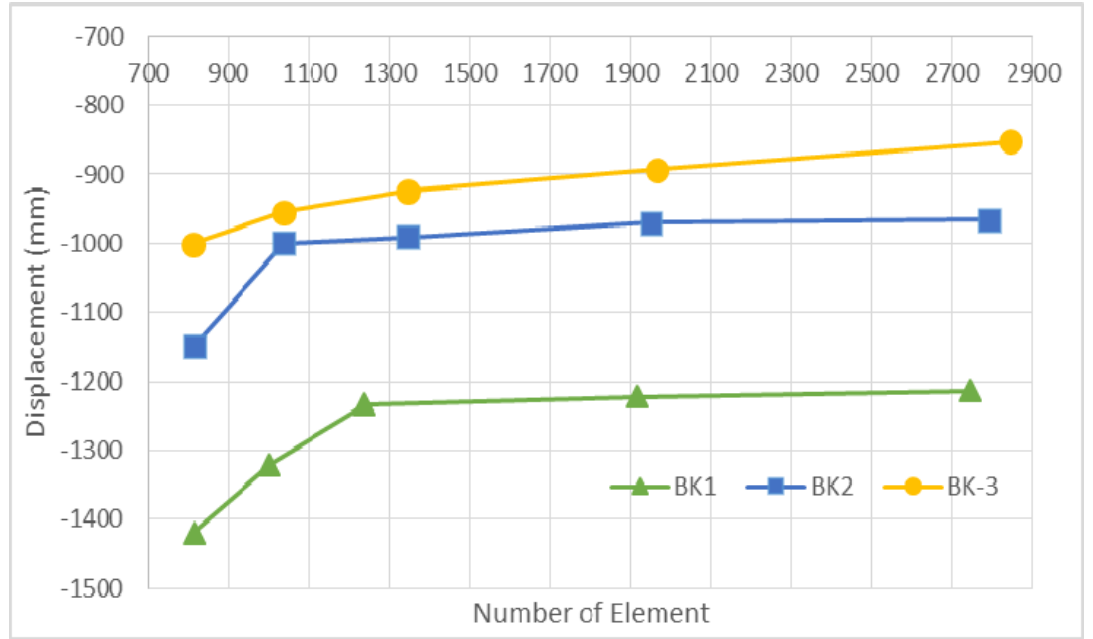

Fig. 4. Result of convergence for all specimens.

\subsection{Load-deflection}

The data obtained from this analysis is the result of the load and displacement relationship shown in Figure 5 with a maximum load of $30 \mathrm{kN}$. The figure depicts that the maximum absolute deflection in BK-2 is $18.03 \mathrm{~mm}$ while the BK-3 test object obtains a deflection value of $22.78 \mathrm{~mm}$. This shows the deflection value of BK-3 is $26.36 \%$ larger than the BK2 test specimen. The biggest deflection occurred in the BK-1 cantilever test object of 28.33 $\mathrm{mm}$, as it is $57.13 \%$ greater compared to sample BK-2 (which has the smallest deflection).

Table 2 explains that loads capable of being received by BK-1 are $11.05 \mathrm{kN}$ whereas model BK-2 can hold a larger load of $13.15 \mathrm{kN}$ and BK-3 cantilever beams are able to receive a $13.95 \mathrm{kN}$ load. From this data, BK-3 is capable to support the highest load compared to others, even though the deflection is also big compared to BK-2.

This study also obtained the value of load and deflection the first time the beam was cracking. Sample BK-1 cracked at $8.203 \mathrm{kN}$ with a deflection of $6.211 \mathrm{~mm}$. The BK-2 cantilever beam cracked when a load of $5.68 \mathrm{kN}$ was reached with a deflection of $2.63 \mathrm{~mm}$. BK-3 cracked at $6.48 \mathrm{kN}$ with a deflection of $2.35 \mathrm{~mm}$.

Table 2 Load - displacement result.

\begin{tabular}{|c|c|c|c|c|}
\hline \multirow{2}{*}{$\begin{array}{c}\text { Beam } \\
\text { Sample }\end{array}$} & \multicolumn{2}{|c|}{ Yield } & \multicolumn{2}{c|}{ Crack } \\
\cline { 2 - 5 } & Force (N) & $\begin{array}{c}\text { Displacement } \\
(\mathbf{m m})\end{array}$ & Force (N) & $\begin{array}{c}\text { Displacement } \\
(\mathbf{m m})\end{array}$ \\
\hline BK-1 & 11058.15 & 28.3342 & 8203.14 & 6.21138 \\
\hline BK-2 & 13157.76 & 18.0315 & 5680.08 & 2.629 \\
\hline BK-3 & 13946.46 & 22.7856 & 6481 & 2.3477 \\
\hline
\end{tabular}




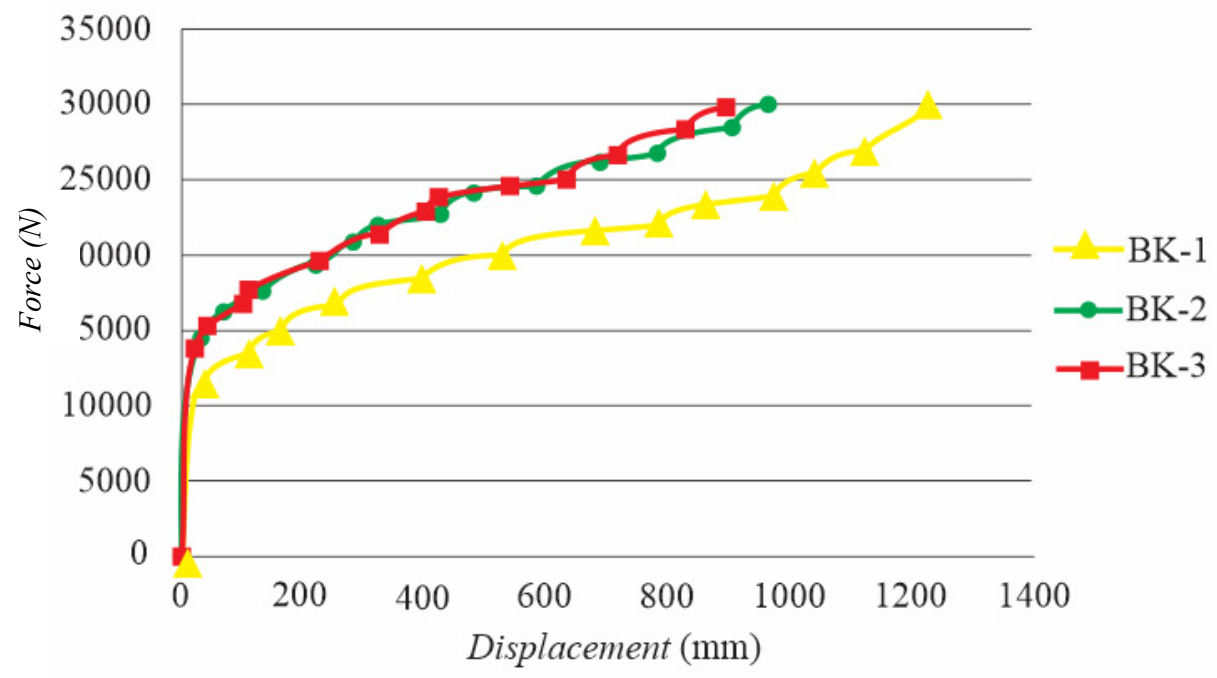

Fig. 5. Force displacement result.

Figure 6.a shows the stiffness of all beams in which BK-2 is the highest rigid beam of $729.71 \mathrm{~N} / \mathrm{mm}$, whereas the BK-1 beam only obtains a stiffness value of $390.39 \mathrm{~N} / \mathrm{mm}$ or only $53.64 \%$ of the stiffness of the BK-2 beam. Beam BK-3 obtains a stiffness value of $612.07 \mathrm{~N} / \mathrm{mm}$, or only $83.88 \%$ of the stiffness of the BK-2 beam. From this stiffness value, it can be concluded that the BK-2 beam has the best stiffness level while the BK-1 beam has the smallest stiffness value.

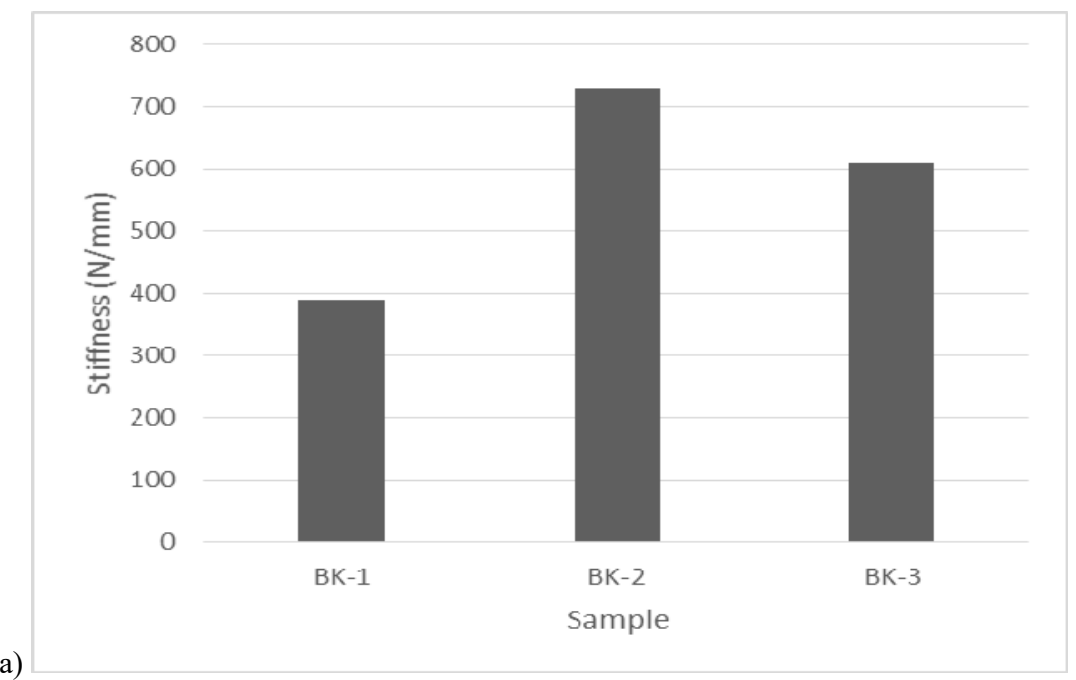


(b)

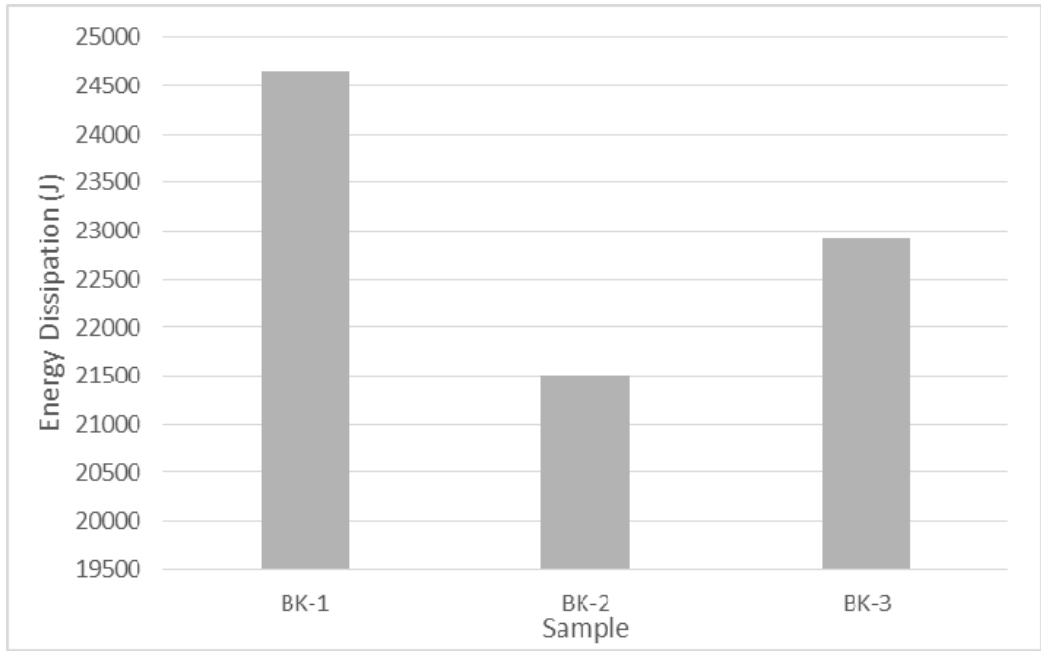

Fig. 6. (a) Stiffness result; (b) Energy dissipation result.

Energy dissipation is any lost energy when the samples are loaded. The amount of energy lost in each model can be seen in Figure 6.b. The smallest loss of energy occurs in BK-2 which is $21511.25 \mathrm{~J}$, while test object BK-1 obtains an energy loss value of 24663.71 J, or $14.65 \%$ higher than BK-2. Sample BK-3 has an energy loss of 22919.15 J, or $6.54 \%$ higher than the BK-2 test specimen. Based on the analysis result, it is found that BK-2 model has the lowest energy loss value given the same load, so it can be concluded that BK-2 is the best model in accepting the load.

\subsection{Stress-strain}

The results of this study also obtained the value of stress and strain on each specimen. Figure 7 shows the results of the stress relationship and strain of all specimens. From the figure it can be seen that the largest stress value found on block BK-2 is $6.38 \mathrm{~N} / \mathrm{mm}^{2}$, while the BK-1 beams get an ultimate stress value of $3.53 \mathrm{~N} / \mathrm{mm}^{2}$ and the BK-3 model beam obtained an ultimate stress value of $6.09 \mathrm{~N} / \mathrm{mm}^{2}$.

The ultimate load is obtained when the largest strain value occurred in BK-1 which is 0.0239 , while the strain value in BK-2 is 0.0158 and the strain value in BK-3 is 0.016 . Stress-strain relationship among those three samples are compared, and from that it can be concluded that BK-2 is the best model because it has largest stress value and small strain. However, the plasticity level of the BK-2 beam still needs to be analysed further. In Table 3 , the value of stress and strain when the beam has reached the yield and ultimate stress can be seen.

Table 3 shows the ductility value of all test specimens in which the beam with BK-1 obtained the highest ductility value of 47.8027 while BK-2 obtained a ductility value of 8.8452 and the brittle beam in BK-3 obtained a value of 7.1516.

Table 3. Stress and strain result.

\begin{tabular}{|c|c|c|c|c|c|}
\hline \multirow{2}{*}{$\begin{array}{c}\text { Type } \\
\text { structure }\end{array}$} & \multirow{2}{*}{ Ductility } & \multicolumn{2}{|c|}{ Strength $\left(\mathbf{N} / \mathbf{m m}^{\mathbf{2}}\right)$} & \multicolumn{2}{c|}{ Strain } \\
\cline { 3 - 6 } & & Yield & Ultimate & Yield & Ultimate \\
\hline BK-1 & 47.8027 & 3.142 & 3.529 & 0.0005 & 0.0239 \\
\hline BK-2 & 8.8452 & 4.892 & 6.385 & 0.0017 & 0.0158 \\
\hline BK-3 & 7.1516 & 4.178 & 6.096 & 0.0022 & 0.0160 \\
\hline
\end{tabular}




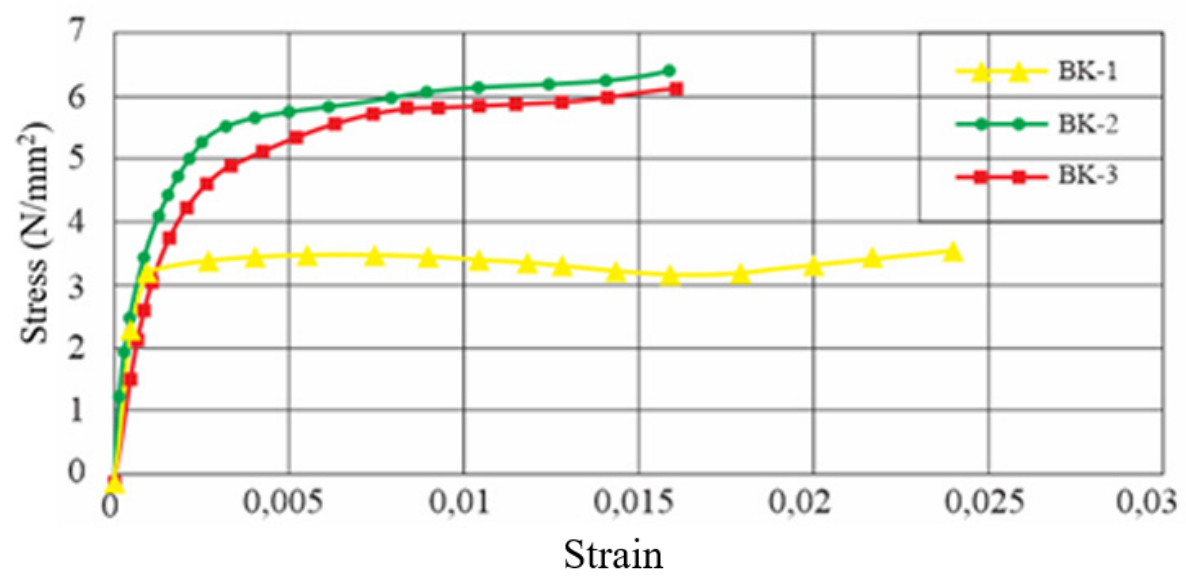

Fig. 7. Stress and strain result.

\subsection{Crack pattern}

In sample BK-1, the first crack occurred near the beam-column connection as shown in Figure 8. This crack occurs when the load reached $8,203 \mathrm{kN}$ with a deformation of 6.21 $\mathrm{mm}$. The first crack in the connector occurs within the load of 9,093 $\mathrm{kN}$ and displacement of $13.61 \mathrm{~mm}$.

In other hand, first crack of sample BK-2 happened near its connection with the load reaching $5.68 \mathrm{kN}$ with a deflection of $2.63 \mathrm{~mm}$. Figure 9 illustrates the crack in the beam connecting device when the load reaches $12,015 \mathrm{kN}$ with a deflection of $15.03 \mathrm{~mm}$.

Model BK-3 experienced the first crack when the load reached $6.481 \mathrm{kN}$ with a deflection of $2.35 \mathrm{~mm}$. Figure 10 illustrates that the crack in the connecting device occurred when the load reached $5.28 \mathrm{kN}$ with a deflection of $5.76 \mathrm{~mm}$. 


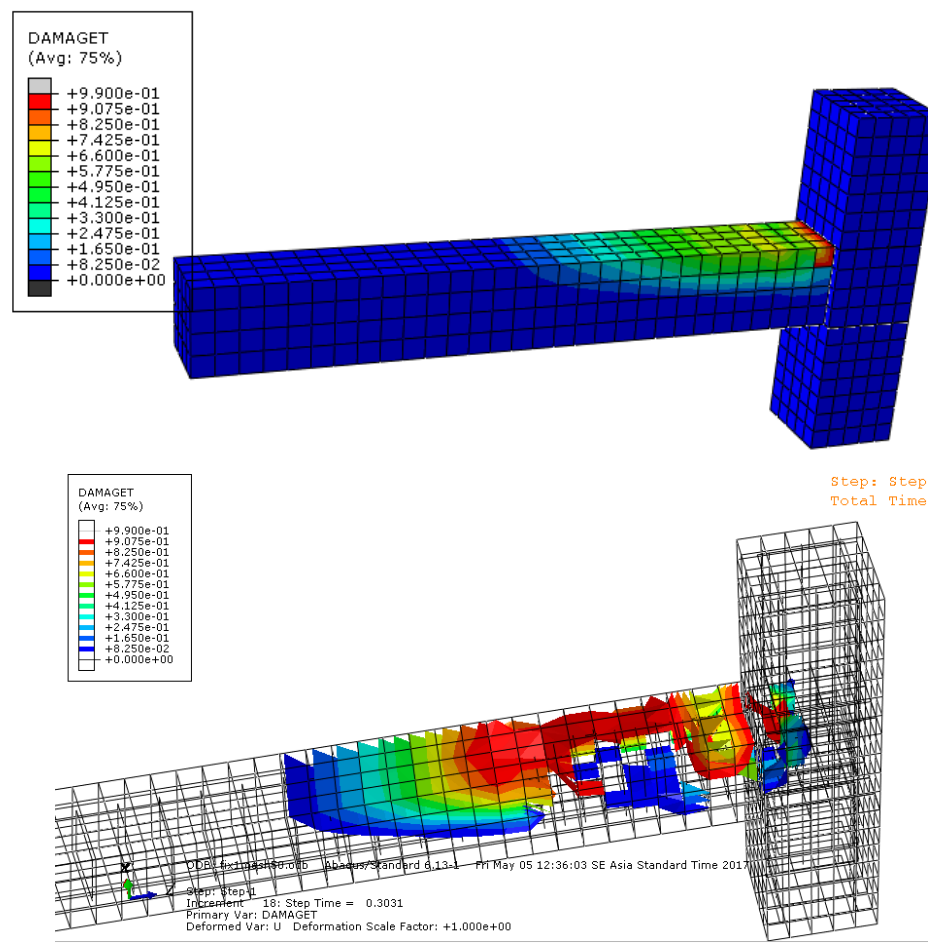

Fig. 8. Crack pattern on concrete precast connection of cantilever beam BK-1.

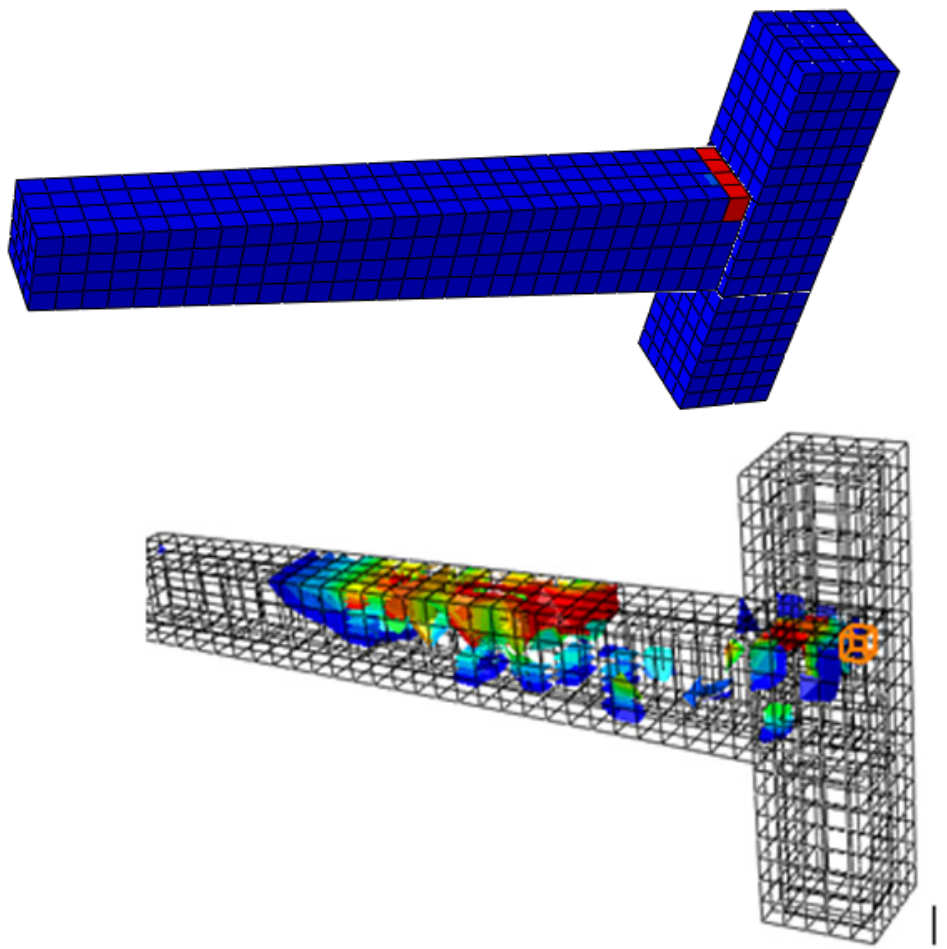

Fig. 9. Crack pattern on concrete precast connection of cantilever beam BK-2. 


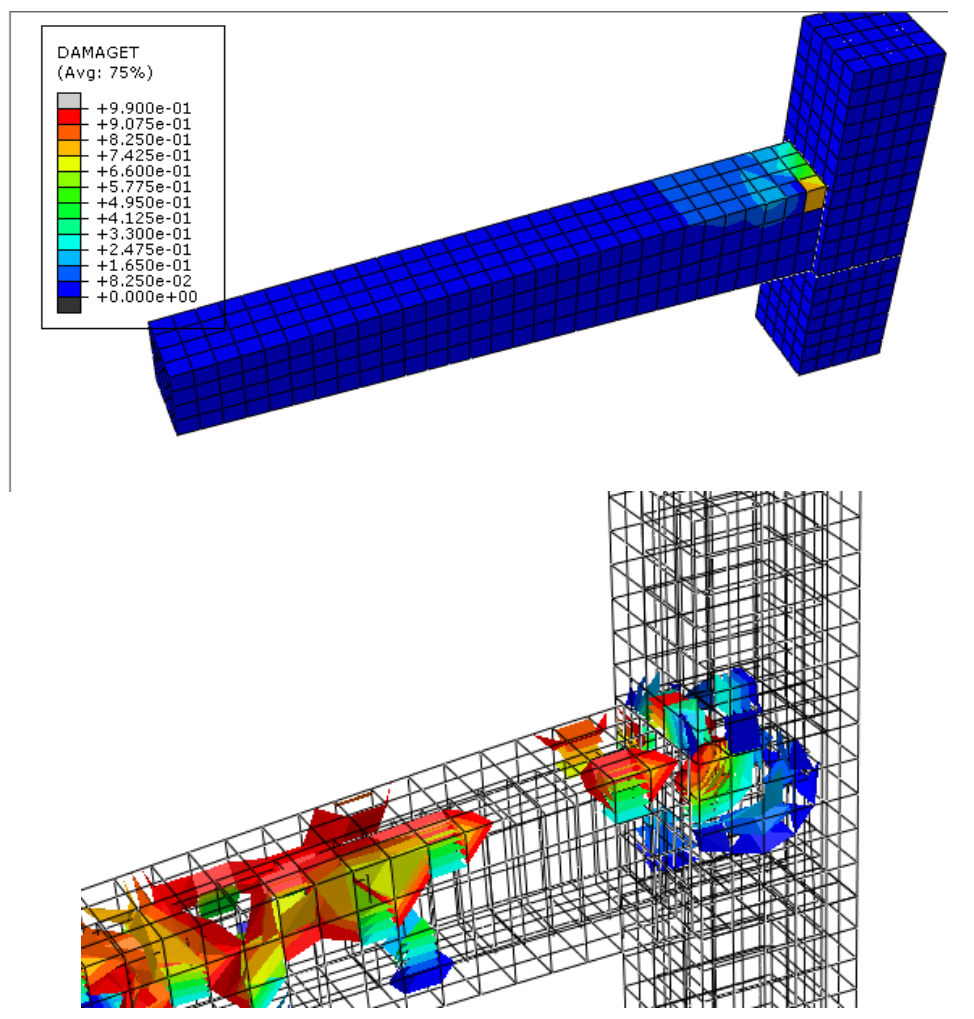

Fig. 10. Crack pattern on concrete precast connection of cantilever beam BK-3.

\section{Conclusion}

Based on the results of numerical analysis using software Abaqus 6.13, from the three specimens it can be concluded that the sample with the smallest stress value is BK-1 (3.53 $\mathrm{N} / \mathrm{mm}^{2}$ ), while the smallest strain is achieved by BK-2 (1.58\%). Unlike with the stress and strain, the smallest deflection is attained by BK-2 with $18.031 \mathrm{~mm}$, with the maximum load obtained by BK-3 at $13.946 \mathrm{kN}$. These results can provide a reference to related researches, and considerations for engineers in the field who use beam-column connections using precast concrete.

\section{References}

1 S. Gawande, Investigations on Effect of Notch on Performance Evaluation of Cantilever Beams, International Journal of Acoustics and Vibrations, Vol 22 No.4, pp 493-500, (2017)

2 H. D. Nelson, A Finite Rotating Shaft Element Using Timoshenko Beam Theory, Journal of Mechanical Design, Vol 102, pp 793-803, (1980)

3 T. Belendez. C. Neipp. A. Belendez, Numerical and Experimental Analysis of a Cantilever Beam: A Laboratory Project to Introduce Geometric Nonlinearity in Mechanics of Materials. International Journal Engineering Edition, Vol 19 No.6, pp885-892, (2003) 
4 H. Lee, Large Deflections of Cantilever Beams of Non-linear Elastic Material Under a Combined Loading, International Journal of Non-Linear Mechanics, Vol 37, pp 439-443 (2002)

5 T. Belendez. C. Neipp. A. Belendez. Large and Small Deflections of a Cantilever Beam, European Journal of Physics, Vol 23, pp 371-379, (2002)

6 B.K. Lee. J. F. Wilson. S.J. Oh, Elastica of Cantilevered Beams with Variable Cross Sections, International Journal Non-Linear Mechanics, Vol 28, pp 579-589, (1993)

7 R. Sethi. S.K. Senapati. D.R.K. Parhi. Analysis of Crack in Structures using Finite Element Method, Global Science and Technology Journal, Vol 2 No.2, pp52-57, (2014)

8 G.M. Owolabi. A.S.J. Swamidas. R. Seshadri, Crack Detection in Beams using Changes in Frequencies and Amplitudes of Frequency Response Functions, Journal of Sound and Vibrations, Vol 265 No.1, pp 1-22, (2003)

9 H. Nahvi. H. Jabbari, Crack Detection in Beams using Experimental Modal Data and Finite Element Model, International Journal of Mechanical Sciences, Vol 47 No.10, pp 1477-1497, (2005)

10 C.C. Lo. S. D. Gupta, Bending of a Nonlinear Rectangular in Large Deflection, Journal of Applied Mechanics, Vol 45 No.1, pp 213-215 (2010)

11 D. Darwin. C.K. Nmai, Energy Dissipation in RC Beams Under cyclic Load, Journal of Structural Engineering, Vol 112 No.8, pp 1829-1846, (1986)

12 S. Kurniawan, Analisis Numerik Perilaku Sambungan Balok Kolom Beton Pracetak Tipe SRPM-PB2, Thesis: Gadjah Mada University, (2014) 